Research Article

\title{
Study on the Applicability of an Improved Pile-Beam-Arch Method of Metro Station Construction in the Upper-Soft and Lower-Hard Stratum
}

\author{
Xinping Guo, ${ }^{1}$ Annan Jiang $\mathbb{D}^{1},{ }^{1}$ and Shanyong Wang $\mathbb{C}^{2}$ \\ ${ }^{1}$ Highway and Bridge Institute, Dalian Maritime University, Dalian 116026, China \\ ${ }^{2}$ ARC Centre of Excellence for Geotechnical Science and Engineering, The University of Newcastle, Callaghan, \\ NewCastle 2308, Australia \\ Correspondence should be addressed to Annan Jiang; jiangannan@163.com
}

Received 4 November 2020; Revised 6 December 2020; Accepted 23 December 2020; Published 8 January 2021

Academic Editor: Yilin Gui

Copyright (C) 2021 Xinping Guo et al. This is an open access article distributed under the Creative Commons Attribution License, which permits unrestricted use, distribution, and reproduction in any medium, provided the original work is properly cited.

The main challenge for metro station construction is to ensure the construction schedule while minimizing the impact on the surrounding environment. Based on the characteristics of the upper-soft and lower-hard stratum in the Dalian city of China, a special structure with six pilot tunnels and three spans of the pile-beam-arch (PBA) method is proposed and applied to the construction of the Labor Park metro station. In this study, laboratory experiments, numerical simulation analysis, and field monitoring data are used to investigate the applicability of six pilot tunnels and three spans of the PBA method in the process of construction. In the process of numerical simulation, the ground surface settlement, arch vertical displacement, the horizontal displacement of rock mass on both sides of the station, and vertical stress of support structure are analyzed. The numerical simulation results are found to be in good agreement with field measurement. Furthermore, the results indicate that, in the construction of six pilot tunnels and three spans of the PBA method, pilot tunnel construction and arch construction have a great influence on the surface settlement. The part of the initial vertical support of the pilot tunnels is removed, which caused the change of the position of maximum vertical stress and the redistribution of vertical stress. Because of reinforcement by side piles on both sides of the station, the horizontal displacement of the rock mass was reduced by $44.76 \%$ compared with that without reinforcement. The six pilot tunnels and three spans of the PBA method can effectively control the surface settlement, arch vertical displacement, and horizontal displacement of the rock mass.

\section{Introduction}

The construction of the metro station is complicated, and the construction period is long. How to reduce the disturbance caused by the station construction to the surrounding environment is the focus of the construction process [1-3]. In past decades, the open-cut method [4] and the cut-and-cover method [5] are the most widely used ways of constructing a metro station. Shakeel and Charles [6] and Zheng et al. [7] studied the influence of the open-cut method of metro station on adjacent bridge piles. These studies have shown that the open-cut method of metro station could produce a significant effect on adjacent piles. Zhou et al. [8] simulated the influence of foundation pit dewatering on the surrounding surface in the process of the open-cut method by using the three-dimensional finite difference method. Hsiung et al. [9] and Hsieh et al. [10] analyzed the influence of foundation pit excavation on the enclosure wall. From the aforementioned research studies, it can be seen that the construction period of the open-cut method is short, but the influence of the construction on the surrounding environment is inevitable. The construction period of the cut-andcover method is longer than the open-cut method. However, the construction site of the cut-and-cover method is located underground, which has little impact on the surrounding traffic $[11,12]$. In the construction process of cut-and-cover method, the enclosure structure has little deformation, which can effectively control the deformation of surrounding soil and the surface settlement, and is beneficial to the protection of adjacent buildings and structures $[13,14]$. 
In the construction process of metro stations in many cities, the cut-and-cover method becomes the first choice of metro station construction to reduce the impact on the existing traffic system [15].

The pile-beam-arch (PBA) method is a new construction method in the cut-and-cover method. The core idea of the PBA method is to form an overall support system composed of the lateral wall support structure and arch initial support structure to ensure sufficient safety during the excavation of the main part of the station and effectively control the settlement of the stratum. The PBA method has its unique advantages in the construction of metro stations and strong applicability to the construction environment $[16,17]$.

Some researchers had studied the PBA method. Chen [18] studied the influence of the excavation sequence of the pilot tunnel with the PBA method on surface subsidence in sand gravel stratum, and the results showed that the underground excavation of the station had no significant effect on the final surface subsidence by applying different excavation sequence of pilot tunnels. Huang et al. [19] studied the PBA construction process of the Suzhou street subway station in Beijing. The main structure of the metro station mainly passes through the gravel and silty clay stratum, and the results show that "effect of group cavities" would appear when a plurality of adjacent pilot tunnels was excavated together. Wang et al. [20] studied the influence of construction with the PBA method on strata and adjacent pipelines based on the research background of the Beijing subway station. Ren et al. [21] studied the excavation quantity and excavation sequence of the pilot tunnels of the PBA method in the loess area. Wang et al. [22] analyzed the ground subsidence during the construction of the metro station with the PBA method by using the empirical formula, related technical specifications, and numerical simulation.

From the aforementioned research studies, it can be seen that the PBA method has been effectively applied in metro station construction. It can effectively control the impact of construction on the surrounding environment. However, in the aforementioned research studies on the PBA method, the station span was small and the stratum in which the station was located was mostly loose and weak. There are few studies on the application effect of the PBA method on the uppersoft and lower-hard stratum.

The geology of the Labor Park metro station of Dalian city is upper-soft and lower-hard stratum, and there are several traffic routes around the station. To reduce the impact on existing traffic, the PBA method was selected for the construction of the station. The main structure of the station is located in a moderately weathered rock mass. The lower rock mass has strong self-stability. Taking advantage of the self-stabilizing ability of the lower rock mass, the conventional eight pilot tunnels and three spans of the PBA method are improved to six pilot tunnels and three spans. The improved PBA method reduces the number of pilot tunnels and adopts steel pipe piles to reinforce rock mass on both sides, thus improving construction efficiency. However, the stability of the improved PBA method in the construction process is still uncertain, so the following research is needed.
To analyze the applicability of six pilot tunnels and three spans of the PBA method in the upper-soft and lower-hard stratum, firstly, the surrounding rock parameters of the station were obtained through laboratory experiments. Then, numerical simulation analysis was carried out based on the obtained surrounding rock parameters. The surface settlement, vertical displacement of arches, rock mass horizontal displacement, and support structure stress are analyzed by combining with the simulation results and field measurement results in the construction process.

\section{Engineering Environment and Improved PBA Method}

The Labor Park metro station of Dalian city is located at the intersection of Jiefang Road and Ziwei Road, along with the north-south layout of Jiefang road. The northeast side of the station is Dalian no. 9 middle school, the southeast side of the station is a residential building, and the west side of the station is Dalian no. 24 middle school. Labor Park metro station is a metro station on Dalian Metro Line 5. It is located in the busy area of the city, and there are many traffic lines around it (Figure 1). During the construction process, the ground settlement around the station should be strictly controlled.

The geological conditions of the Labor park metro station are the upper-soft and lower-hard stratum. The stratum crossed by the main structure of the station is moderately weathered slate. Taking advantage of the selfstabilizing ability of the lower rock mass, the conventional eight pilot tunnels and three spans of the PBA method are improved to six pilot tunnels and three spans. A special structure with six pilot tunnels and three spans of the PBA method is proposed for station construction. The improved PBA method reduces the number of pilot tunnels, and steel pipe piles are selected on both sides to reinforce rock mass (Figure 2). The main part of the station is a double island station. The depth of the burial at the top of the station is $20.5 \mathrm{~m}$. The station length of Labor Park station is about $191.2 \mathrm{~m}$, the excavation width is about $25.64 \mathrm{~m}$, and the main body height is about $17.75 \mathrm{~m}$.

According to the predesigned construction plan, the construction process of the Labor Park metro station is divided into four construction procedures. Figure 2 shows the stages of construction.

(1) Construction process of six pilot tunnels

The construction stages include the excavation and the support of the pilot tunnels. The excavation sequence of predesigned six pilot tunnels is A1-A2B1-B2-C1-C2 (stage 1-3).

(2) Construction process of steel pipe piles, middle piles, and beams

When the construction stages of pilot tunnels are completed, side piles, beams, and middle piles shall be constructed. During this period, the void behind the initial support is backfilled with concrete (stage 4 ). 


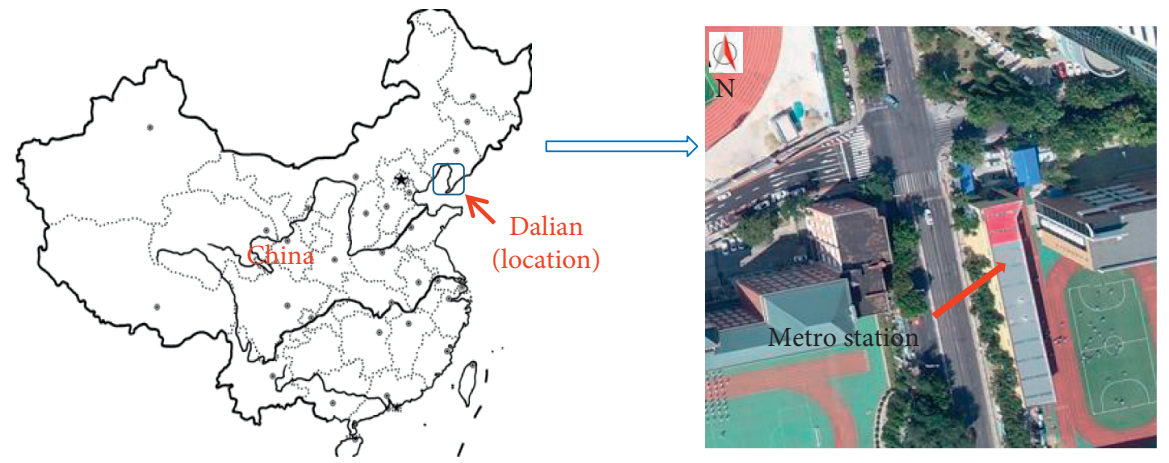

Figure 1: The location of the metro station.

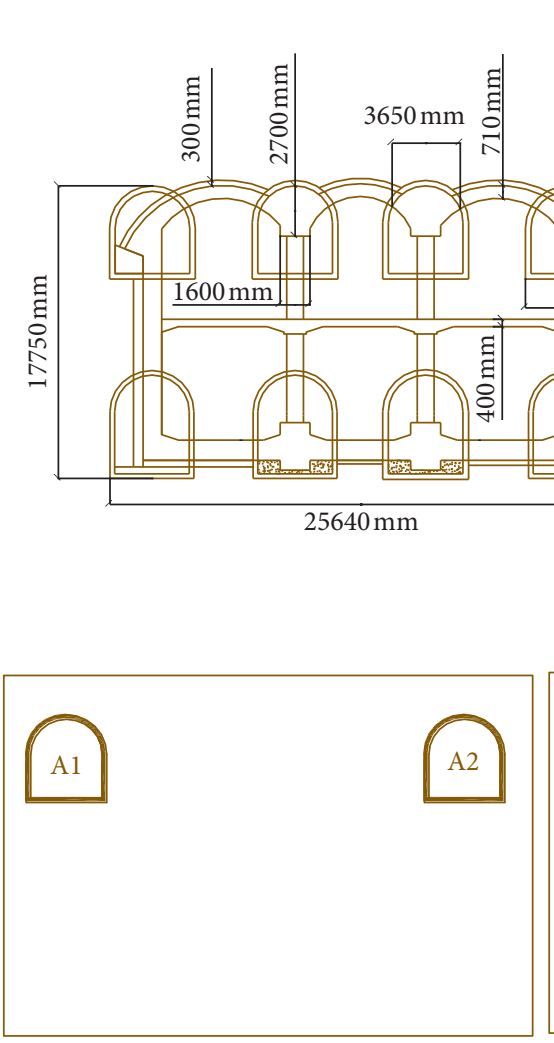

(a)

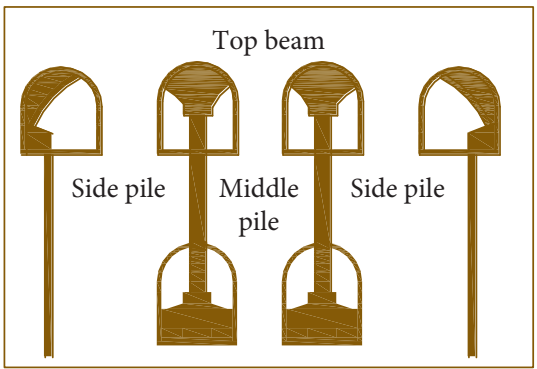

(d)
Filled soil Silty clay Strongly weathered slate

Moderately weathered slate

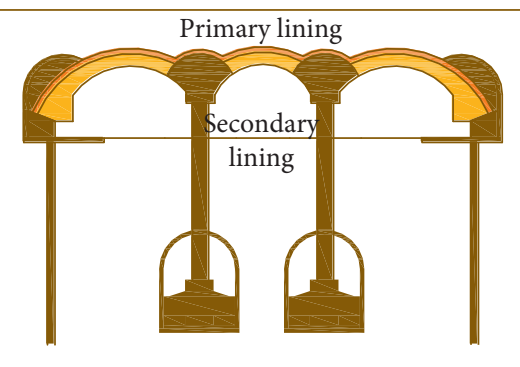

(e)

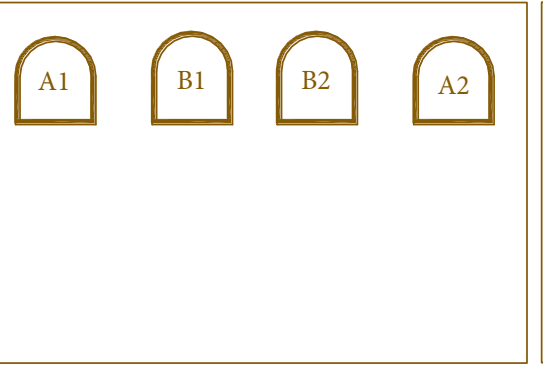

(b)
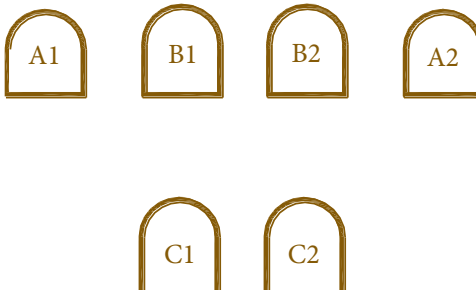

(c)

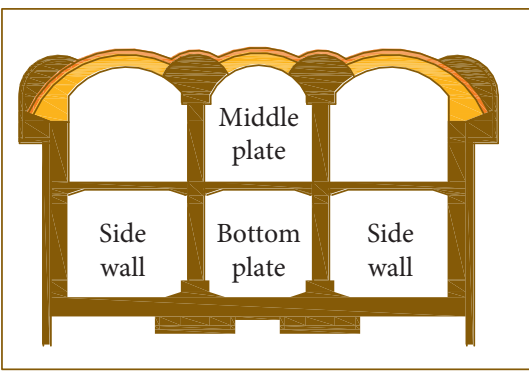

(f)

Figure 2: Construction sequence of the PBA method. 
(3) Construction process of arches

This stage includes the excavation of the rock mass between the pilot tunnels, removal of vertical support of pilot tunnels, and installation of the primary lining and secondary lining (stage 5).

(4) Construction process inside the metro station

This stage includes the excavation of rock mass inside the metro station and the construction of the middle plate, bottom plate, and side wall (stage 6).

The improved PBA method made full use of the stability of rock mass, reduced the number of pilot tunnels, shortened the construction period, and reduced the project cost.

\section{Field Monitoring Data Analysis}

To effectively monitor the impact of the station construction process on the surrounding environment, a surface settlement monitoring section is arranged every $10 \mathrm{~m}$ along the excavation direction of pilot tunnels. The plane layout of ground surface settlement monitoring points is shown in Figure 3.

The rules of different surface settlement monitoring sections are similar, so only one section (DBC-07) is selected for analysis. Figure 4 shows the field monitoring data results of the ground surface in the construction stage of pilot tunnels.

The earliest ground settlement is located directly above the excavation pilot tunnels in the early stage of the construction of pilot tunnels. In the later stage of guide tunnel excavation, with the successive excavation of each pilot tunnel, the surface settlement increases rapidly, and the closer it is to the center of the station, the greater the surface settlement. After the construction of the pilot tunnels, the maximum settlement value on the surface is $-7.54 \mathrm{~mm}$. This shows that when several adjacent pilot tunnels are excavated at the same time, each pilot tunnel would affect each other, and then the construction disturbance will be amplified, showing the "effect of group cavities." [19]

\section{Laboratory Tests for Rock Specimens of Engineering}

In the process of construction, the determination of support schemes is mainly based on the geological exploration data. Because of the limitations of the exploration techniques and the complexity of the construction environment, the applicability of the preconstruction schemes often have some disadvantages and the supporting strength may be insufficient, which may lead to construction risks. In the construction of six pilot tunnels and three spans of the PBA method, the self-stability of the lower rock mass needs to be fully utilized. To ensure the safety of the later construction, the exposed rock mass was selected for sample preparation during the actual construction process of six pilot tunnels. Rock specimens are tested by triaxial experimental instruments. The physical and mechanical properties of rock mass are analyzed (Figure 5).
The test is carried out according to four different confining pressure levels: $0 \mathrm{MPa}, 5 \mathrm{MPa}, 15 \mathrm{MPa}$, and $30 \mathrm{MPa}$. Figure 6 shows the full stress-strain curve of the triaxial test of rocks under different confining pressures. As can be seen, the triaxial compressive strength of rocks increases with the increase of the confining pressure applied. The overall properties of the rocks are good. Some rocks have joint development.

Chen et al. [23] studied the determination of rock mass mechanical parameters used in the numerical simulation and established a practical and effective method to determine the physical and mechanical parameters of rock mass in the numerical simulation. Based on this method, the mechanical parameters of moderately weathered slate in the numerical simulation process were determined according to the experimental results, as shown in Table 1.

\section{Model Establishment and Parameter Selection}

During the construction of the six pilot tunnels of the station, the three-dimensional numerical model is established according to the construction conditions. Flac3D software is used to simulate the actual construction of six holes and three spans of the PBA method in Labor Park station. The size of the three-dimensional numerical model is $140 \mathrm{~m} \times 20 \mathrm{~m} \times 60 \mathrm{~m}$, which consists of 98180 zones, as shown in Figure 7. The four side boundaries of the model have restrained the horizontal movements. The displacements in the three directions at the bottom of the model are all constrained. The surrounding soils of the subway station are modeled as Mohr-Coulomb material, and all the concrete structures of the metro station are modeled as an elastic material. Figure 8 shows the support structure model of the station. In the actual construction process, the side pile was composed of steel pipe pile and concrete inside the pile. The diameter and thickness of the steel pipe pile were $219 \mathrm{~mm}$ and $10 \mathrm{~mm}$, respectively. The inside of steel pipe pile was filled with C25 concrete. The weighted average weight of the steel pipe pile combined with concrete was considered, and the unit weight of the side pile was selected as $30 \mathrm{kN} / \mathrm{m}^{3}$. The parameters of soil and rock determined according to geological survey data, and laboratory test results are shown in Table 1.

\section{Result Analysis}

6.1. Layout of the Numerical Monitoring Points. In an investigation of PBA method construction, the ground surface settlement, vertical displacement of arches, support structure stress, and rock mass horizontal displacement are important references. Corresponding to the position of the actual monitoring points on the site, the layout of the monitoring points in the simulation process is carried out. The layout of surface settlement monitoring points corresponds to the $\mathrm{DBC} 07$ section measured on the site. The arrangement of monitoring points is shown in Figure 9. 


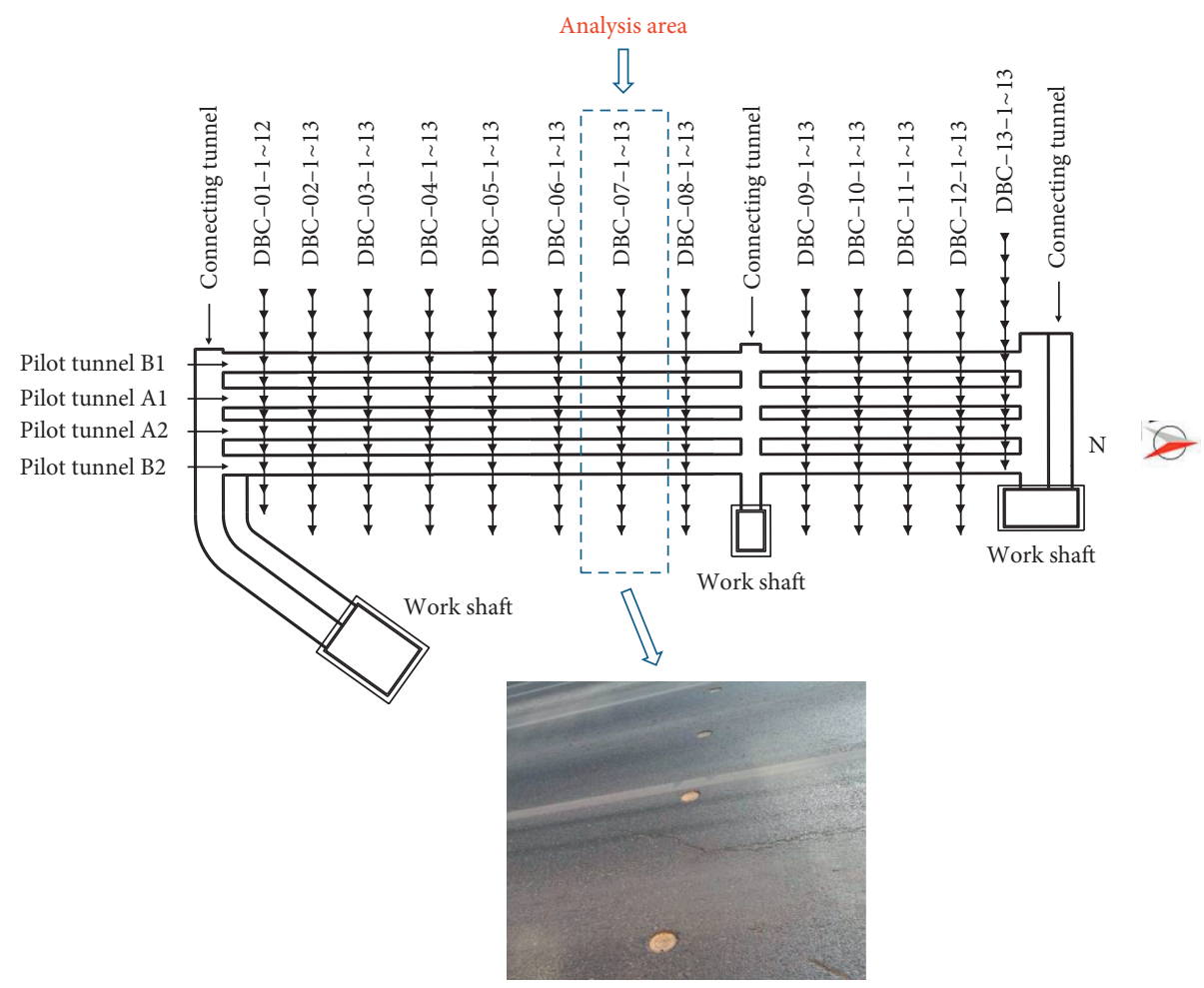

FIGURE 3: The plane layout of ground surface settlement monitoring points.

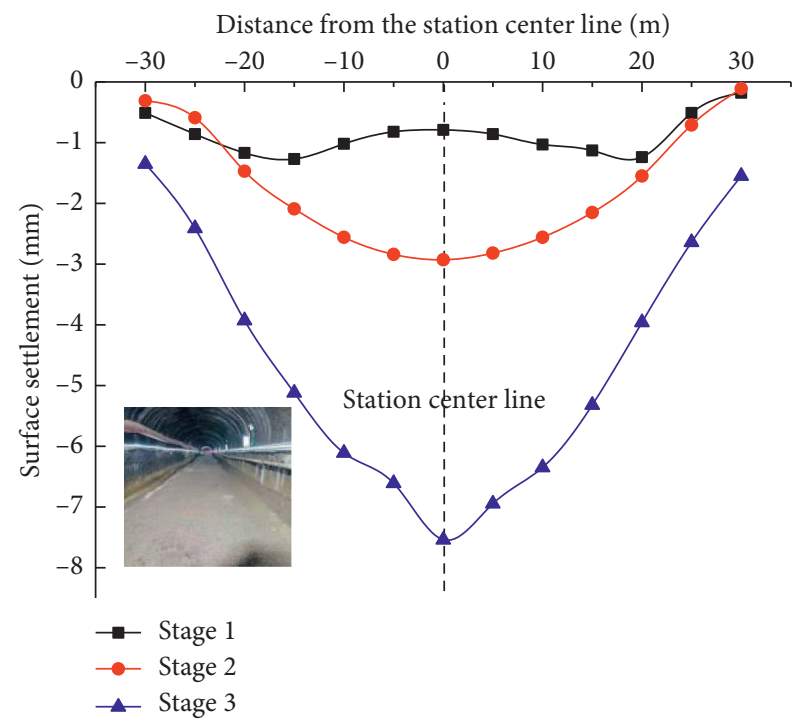

FIGURE 4: Surface settlement curves during the construction of pilot tunnels.

6.2. Analysis of Ground Surface Settlement. Figure 10 shows the rules of the surface settlement monitoring section in the whole construction simulation process of the station. The following can be observed:

(1) During the stage of the excavation of pilot tunnels A1 and A2, the surface settlement curve presents the shape of double grooves. The location with the largest surface settlement is directly above the two pilot tunnels. The maximum settlement value on the surface at the top of pilot tunnels $A 1$ and A2 are $-1.11 \mathrm{~mm}$ and $-1.08 \mathrm{~mm}$. After the completion of the excavation of pilot tunnels B1 and B2, the surface settlement curve changes from double grooves to single grooves, the position with the maximum surface settlement gradually changes from directly above the pilot tunnels to above the centerline of the station, and the maximal settlement value of surface is $-3.31 \mathrm{~mm}$. With the successive excavation of each pilot tunnel, the space between adjacent pilot tunnels becomes smaller and each pilot tunnel affects each other, and the "effect of group cavities" gradually appears. After the excavation of lower pilot tunnels $\mathrm{C} 1$ and $\mathrm{C} 2$, the location of the largest surface settlement does not change. However, the excavation of $\mathrm{C} 1$ and $\mathrm{C} 2$ increases to a surface settlement of $-3.53 \mathrm{~mm}$, accounting for $51.6 \%$ of the total surface settlement in the construction stages of six pilot tunnels. The results show that the excavation of the lower pilot tunnels causes further disturbance to the surface and the superposition effect of the upper and lower pilot tunnels has a greater impact on the surface.

(2) During the construction stage of side piles, middle piles, and beams, the maximum settlement value of the surface is $-7.52 \mathrm{~mm}$. The surface settlement increment caused by the stage was only $0.68 \mathrm{~mm}$, indicating that the excavation process causes little disturbance to the ground surface.

(3) After the construction stage of arches, the maximum settlement value of the surface is $-15.32 \mathrm{~mm}$. The 


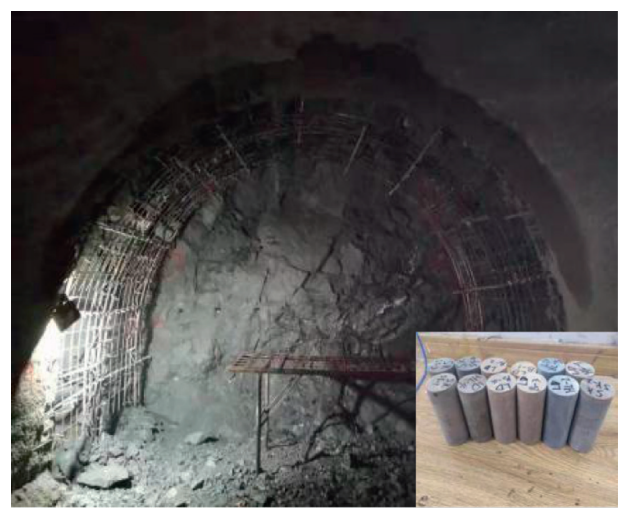

(a)

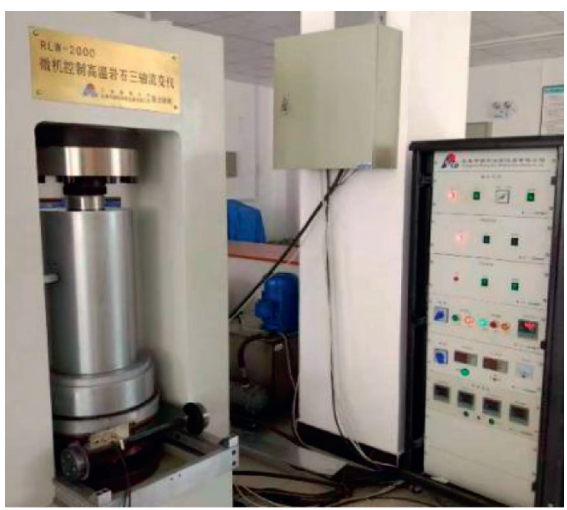

(b)

FiguRE 5: Experimental process of rock mass in the station. (a) Rock specimen collection and preparation. (b) Triaxial experimental instrument.

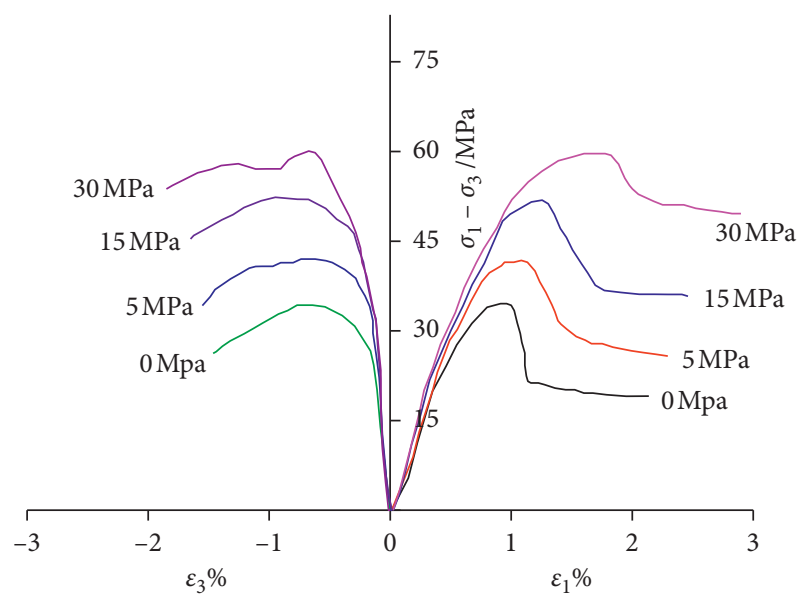

Figure 6: Stress-strain curve of moderately weathered slate.

TABLE 1: Material properties.

\begin{tabular}{lccccc}
\hline Material & $\mu$ & $\begin{array}{c}\gamma \\
\left(\mathrm{kN} \cdot \mathrm{m}^{-3}\right)\end{array}$ & $\begin{array}{c}\mathrm{E} \\
(\mathrm{MPa})\end{array}$ & $\begin{array}{c}\mathrm{c} \\
(\mathrm{kPa})\end{array}$ & $\begin{array}{c}\varphi \\
\left({ }^{\circ}\right)\end{array}$ \\
\hline $\begin{array}{l}\text { Filled soil } \\
\text { Silty clay }\end{array}$ & 0.40 & 17.0 & 13 & 10 & 15 \\
$\begin{array}{l}\text { Strongly weathered } \\
\text { slate }\end{array}$ & 0.35 & 20.3 & 42 & 47 & 17 \\
$\begin{array}{l}\text { Moderately weathered } \\
\text { slate }\end{array}$ & 0.28 & 22.0 & 180 & 60 & 30 \\
$\begin{array}{l}\text { Primary lining } \\
\text { Secondary lining }\end{array}$ & 0.23 & 27.0 & 1200 & 170 & 38 \\
$\begin{array}{l}\text { Side pile } \\
\text { ide }\end{array}$ & 0.20 & 23.0 & 25000 & - & - \\
& 0.20 & 25.0 & 28000 & - & - \\
\hline
\end{tabular}

increment of surface settlement caused by the stage is $-7.71 \mathrm{~mm}$. The increment of ground surface settlement is relatively obvious.

(4) After the construction process inside the metro station, the increment of ground surface settlement is only $-1.98 \mathrm{~mm}$. The results show that after the construction of arches, the support system composed of arches, side piles, middle piles, and beams has a good support effect on the surrounding rock mass of the station.

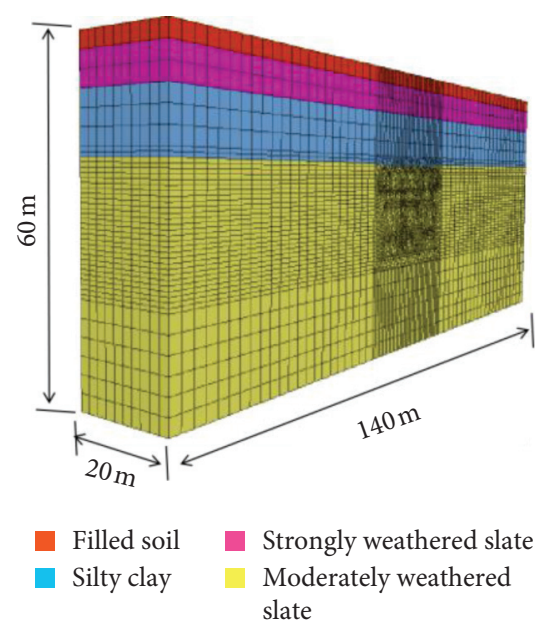

FIgURE 7: Three-dimensional numerical model.

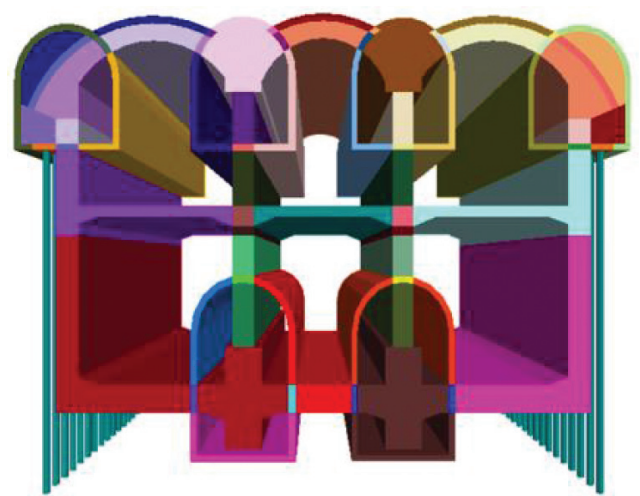

FIGURE 8: Support structure model of the station.

After the construction simulation of the station is finished, the maximum settlement caused by station construction to the surface is $-17.21 \mathrm{~mm}$, and the surface settlement control value in the actual construction process is $-25 \mathrm{~mm}$, indicating that the influence of station construction on the surface is within the control range. The surrounding environment of the station is also in a safe state. 


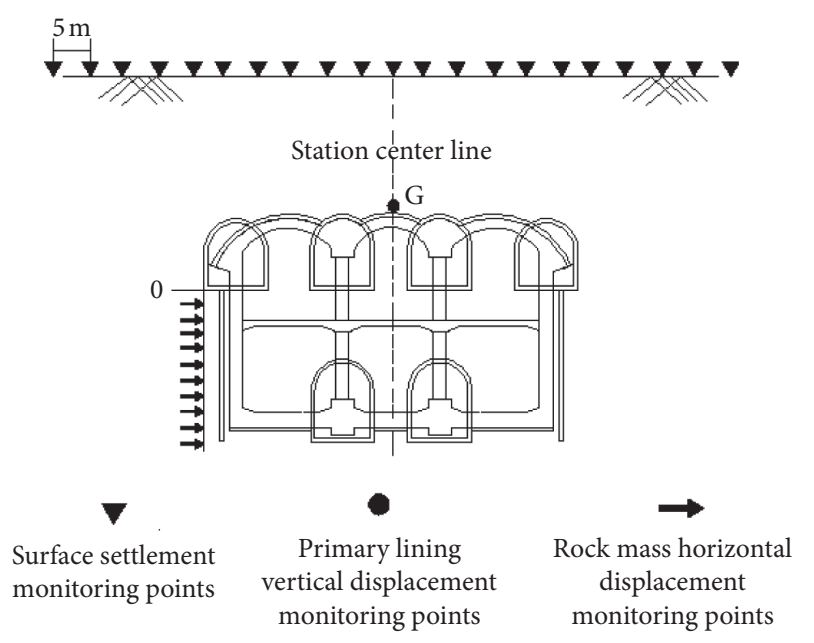

FIGURE 9: Diagram of the location of the monitoring points.

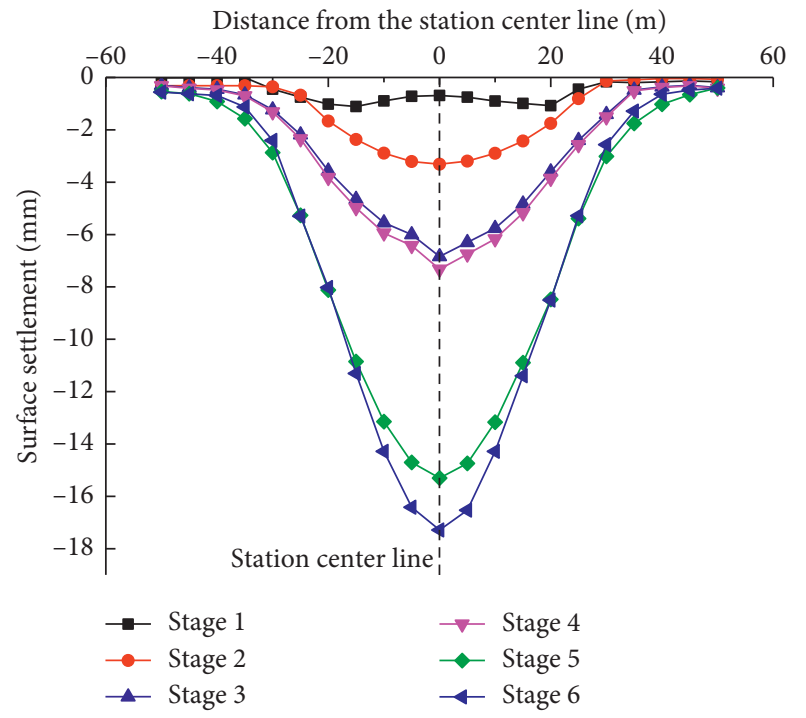

FIGURE 10: The surface settlement at different construction stages.

The ratio of surface settlement to total settlement in the four construction processes of pilot tunnel construction, side piles + middle piles + beam construction, arch construction, and inside the metro station construction is $38.7 \%, 4 \%$, $44.8 \%$, and $11.5 \%$, respectively. The results show that, among the six pilot tunnels and three spans of the PBA method construction process, the two stages that have the greatest impact on the surface settlement are the pilot tunnel construction and the arch construction.

Figure 11 shows the simulation results and field monitoring results of ground settlement at the end excavation of pilot tunnels (stage 3 ). The surface settlement curve presented a single groove. The locations where the maximum settlement occurs are directly above the centerline of the metro station. The amount of surface settlement gradually decreased from the central line of the metro station to both sides. Field monitoring results show that the maximum settlement value of the surface is $-7.54 \mathrm{~mm}$. The value of the simulation results is $-6.84 \mathrm{~mm}$. The numerical simulation results are close to the field monitoring data. Therefore, the numerical simulation of the construction process of the metro station is reasonable. Through the comparison and analysis of the field monitoring results and the numerical simulation results, the feasibility of model parameter selection is corrected, which shows that the selection of model parameters is feasible. The parameters selected by the model can be used to simulate the later excavation process of the station.

6.3. Displacement Analysis of Arches and Rock Mass on Both Sides. The vertical displacement of the arches is paid more attention in the actual construction process, and the maximum allowable vertical displacement value of the arches is $30 \mathrm{~mm}$. The construction process of arches is divided into four construction processes: (1) rock mass excavation between pilot tunnels B1 and B2 and the installation of primary lining; (2) removal of the vertical supports of pilot tunnels B1 and B2 and installation of the secondary lining; (3) rock mass excavation between pilot tunnels A1, B2 and pilot tunnels A2, B2 and the installation of primary lining; and (4) removal of the vertical supports of pilot tunnels A1, B2 and pilot tunnels A2, B2 and the installation of the secondary lining, as shown in Figure 12.

The construction process of metro station substructure is divided into two construction processes: (1) the inner rock mass of the station is excavated to the installation location of the middle plate below $5 \mathrm{~m}$, and then the middle plate and side walls are constructed; (2) the inner rock mass of the station is excavated to the bottom of the station, and then the bottom and side walls are constructed, as shown in Figure 13.

Figure 14 shows the vertical displacement of measuring point G. As can be seen, in the construction stages of arches, the vertical displacement growth rate of the monitoring points shows a tendency of increasing first, then decreasing, and then increasing again. The results show that the removal of the vertical support of the pilot tunnels caused great disturbance to the stability of the station support structure. 


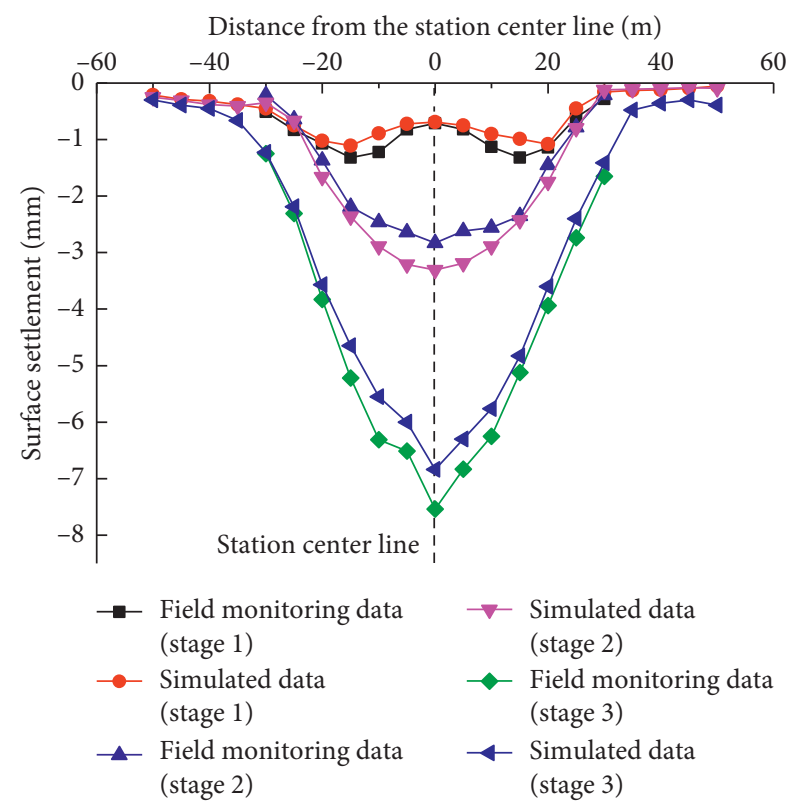

Figure 11: The data curve of surface settlement.

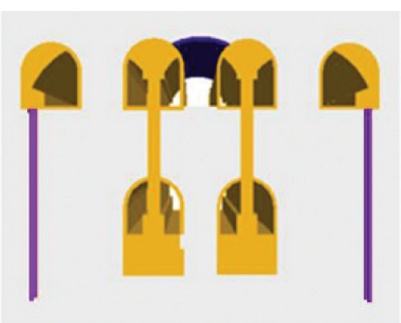

(a)

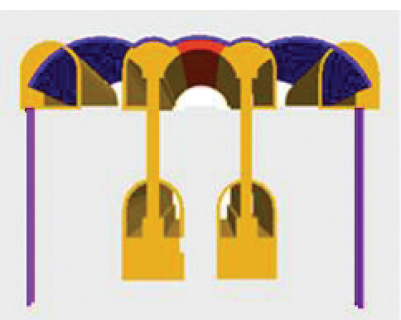

(b)

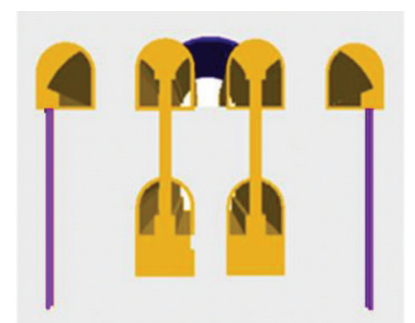

(c)

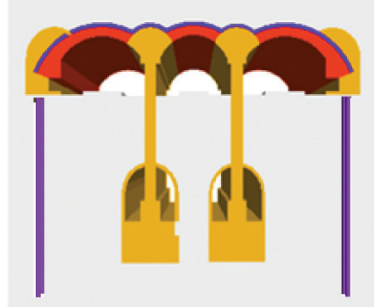

(d)

Figure 12: The construction process of arches. (a) Stage 5-1. (b) Stage 5-2. (c) Stage 5-3. (d) Stage 5-4.

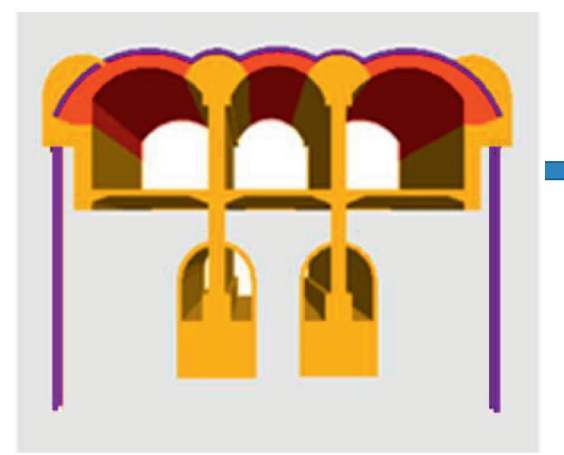

(a)

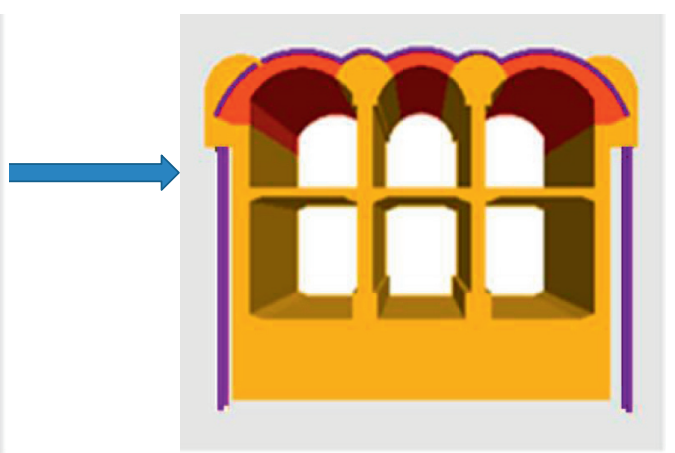

(b)

FIGURE 13: The construction process inside the metro station. (a) Stage 6-1. (b) Stage 6-2.

The maximum vertical displacement of measuring point $\mathrm{G}$ is $-15.9 \mathrm{~mm}$. During the construction process of the metro station substructure, the vertical displacement of measuring point $\mathrm{G}$ caused by the stage is $1.4 \mathrm{~mm}$. The results show that the construction process inside the metro station caused little disturbance to the supporting structure. After the completion of the station construction, the maximum vertical displacement value of the arches is $17.3 \mathrm{~mm}$, which is less than the control value of $30 \mathrm{~mm}$.

In the construction of inside the metro station, the horizontal displacements of the rock masses on both sides of the station are shown in Figure 15. As can be seen, the rock masses on both sides moved horizontally to the interior of the station. The position with the maximal horizontal 


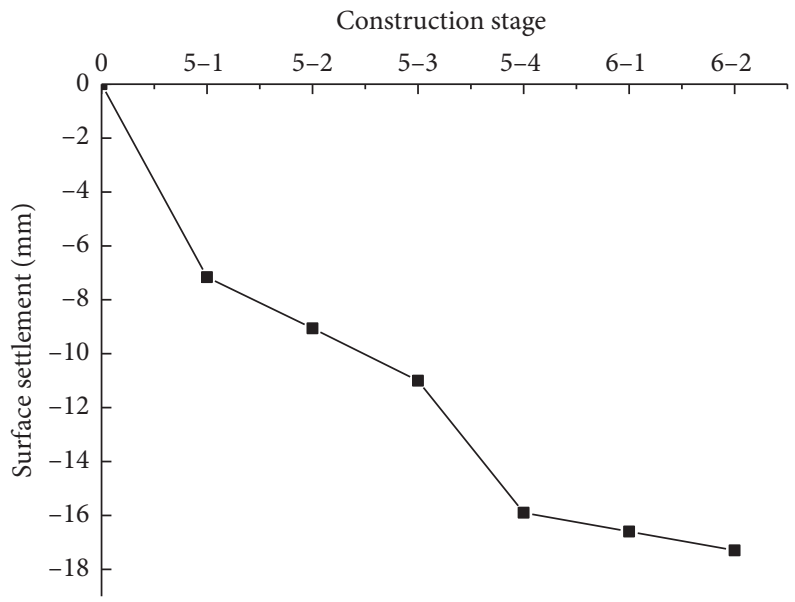

Figure 14: Vertical displacement of measuring point G.

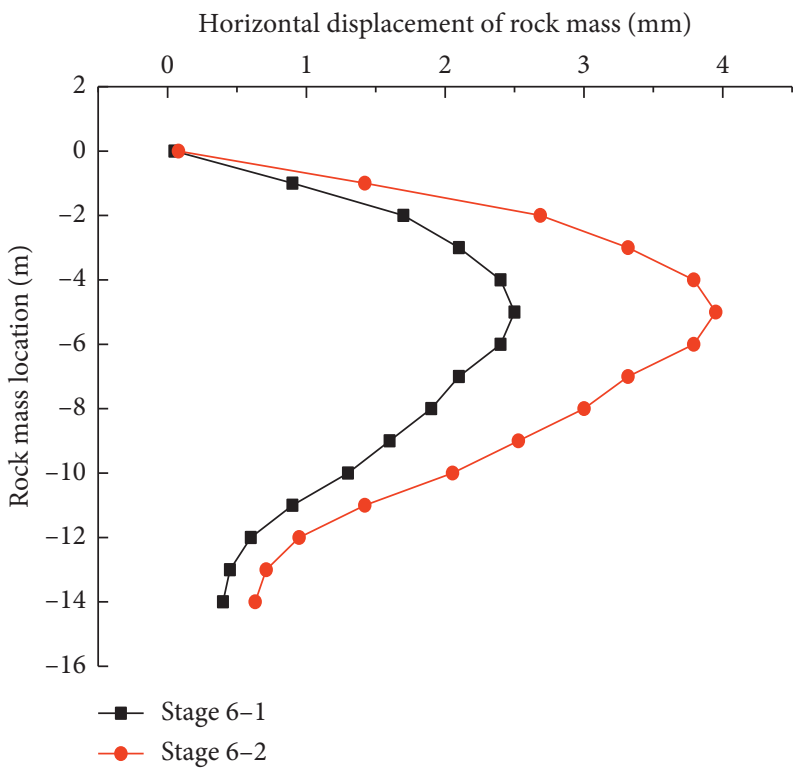

FIGURE 15: Horizontal displacement of rock mass.

displacement is located about $6 \mathrm{~m}$ below the arch foot. The maximum horizontal displacement of the rock mass is $3.96 \mathrm{~mm}$, which is less than the monitoring control value of $10 \mathrm{~mm}$. The arches extend outward under the pressure of the upper soil, which effectively limited the movement of the rock mass at the foot of the arches to the interior of the station.

6.4. Stress Analysis of Arches and Piles. Figure 16 presents the stress in the construction process of arches. As can be seen, after the excavation of rock mass and primary lining construction between pilot tunnels $\mathrm{B} 1$ and $\mathrm{B} 2$, the maximum stress of the supporting structure is $-2.75 \mathrm{MPa}$, which is located on the vertical supports of pilot tunnels B1 and B2. After the removal of the vertical support of pilot tunnels B1 and B2 and the installation of the secondary lining, the maximum stress of the supporting structure is $-3.0 \mathrm{MPa}$, which is located on the vertical primary supports of the pilot tunnels A1 and A2. After the secondary lining of the arch is formed, the maximum stress of the supporting structure is $-3.5 \mathrm{MPa}$, which is located on the middle piles.

The results show that with the excavation of rock mass between adjacent pilot tunnels and the removal of vertical primary branches of pilot tunnels, the position of supporting structure bearing the maximum stress changed from the vertical support of pilot tunnels to the middle piles. During the construction process, the stress conversion is relatively violent, and the vertical stress is redistributed, which caused great disturbance to the ground surface. Therefore, during the removal of the vertical support of pilot tunnels, the speed should not be too fast. Attention should be paid to the monitoring data to prevent the occurrence of dangerous accidents.

Figure 17 shows the stresses of the middle piles during the construction process inside the metro station. As can be seen, middle piles are an important bearing structure 


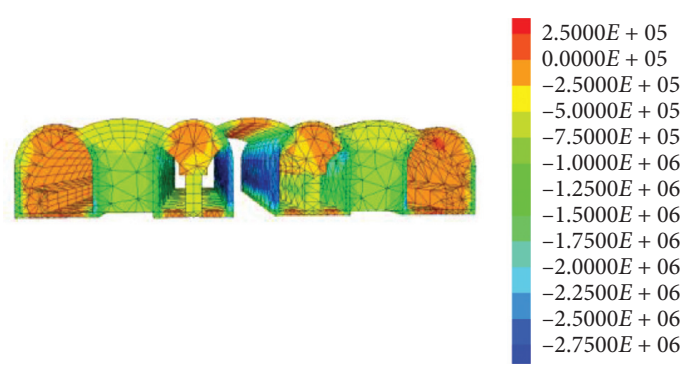

(a)

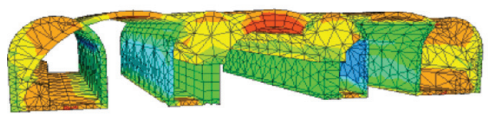

(c)

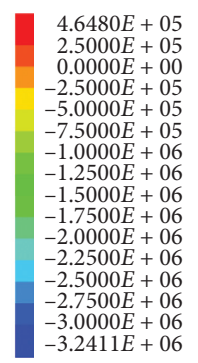

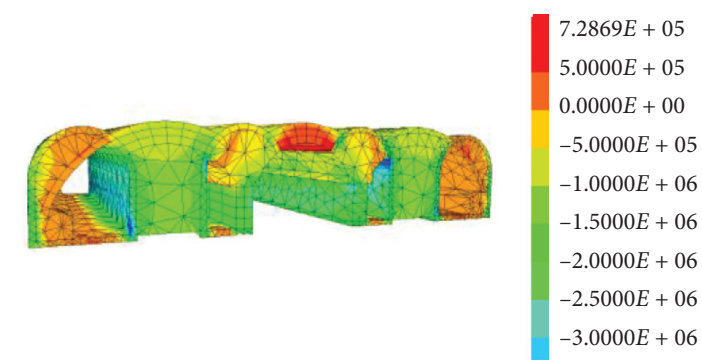

(b)

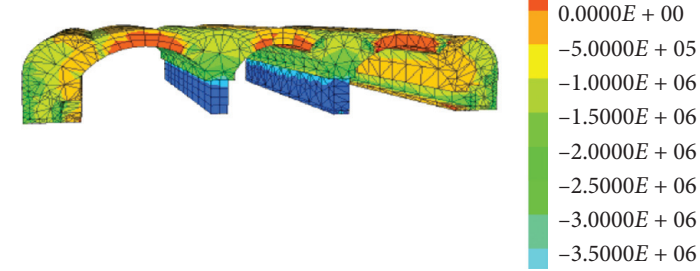

(d)

Figure 16: Principal stress of arches (pa). (a) Stage 5-1. (b) Stage 5-2. (c) Stage 5-3. (d) Stage 5-4.

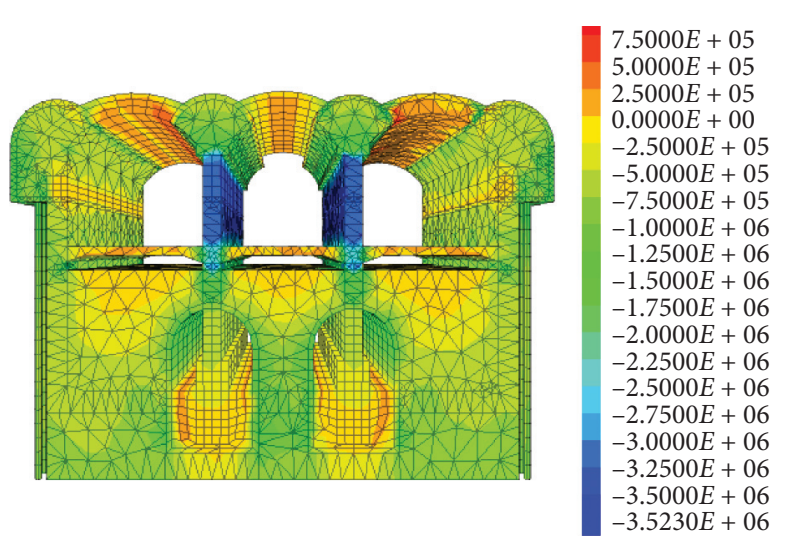

(a)

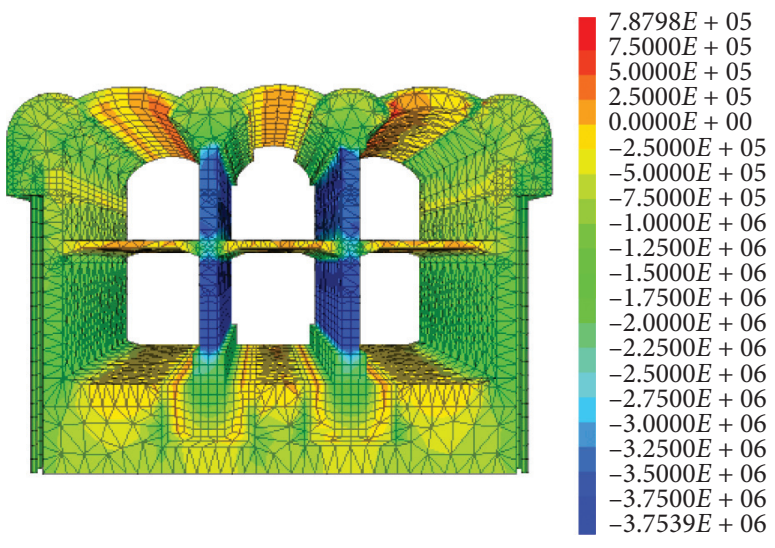

(b)

Figure 17: Principal stress of middle columns (pa).

in the supporting structure. With the excavation of the rock mass inside the metro station, the stresses of the middle piles are transferred from the upper part to the whole piles. After the excavation of the station is completed, the maximum stress value of the middle piles is $-3.75 \mathrm{MPa}$. The calculated stresses of middle piles did not exceed the design strength.

\section{Discussion}

To improve the stability of the rock mass around the station, side piles are used to reinforce the rock mass (Figure 18). The side piles on both sides are steel pipe piles with a diameter of $219 \mathrm{~mm}$, the pile spacing is $0.9 \mathrm{~m}$, and the bottom of the pile is $1 \mathrm{~m}$ under the bottom plate. The effect of side piles on both sides of the station in the construction process is analyzed.

Figures 19 and 20 show the surface settlement and the horizontal displacement curves of the rock mass on both sides of the station after the construction with and without side piles. The ground settlement and horizontal displacement of rock mass on both sides of the station are compared and analyzed in the two cases of construction with side piles and without side piles, under the use of side piles, the ground surface settlement decreased by $20.62 \%$, and the horizontal displacement of the rock mass on both sides of the station decreased by $44.76 \%$. The use of side piles effectively limited the surface settlement and the horizontal displacement of the rock mass on both sides of the station. 


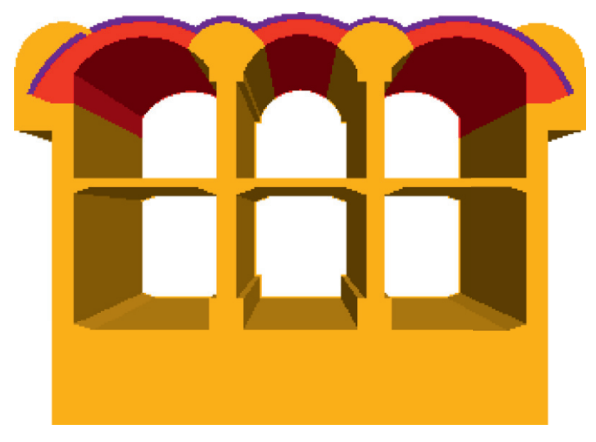

(a)

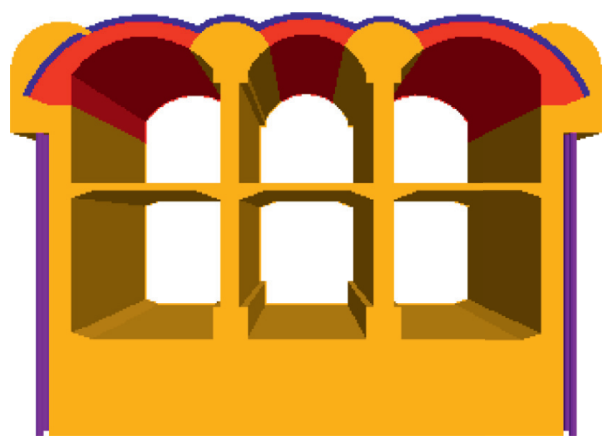

(b)

FIgURE 18: The support structure of the station with and without steel pipe piles. (a) Without side piles. (b) With side piles.

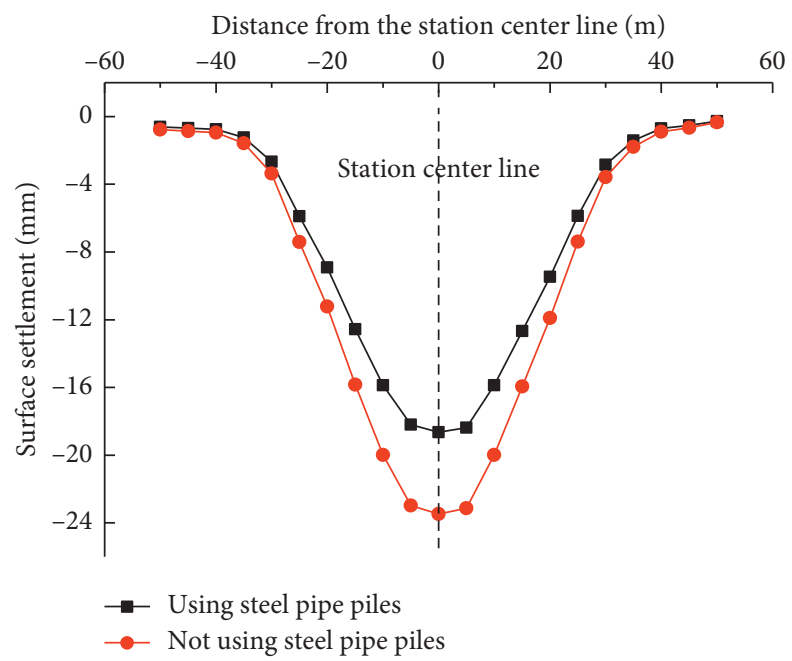

FIgURE 19: The surface settlement with and without steel pipe piles.

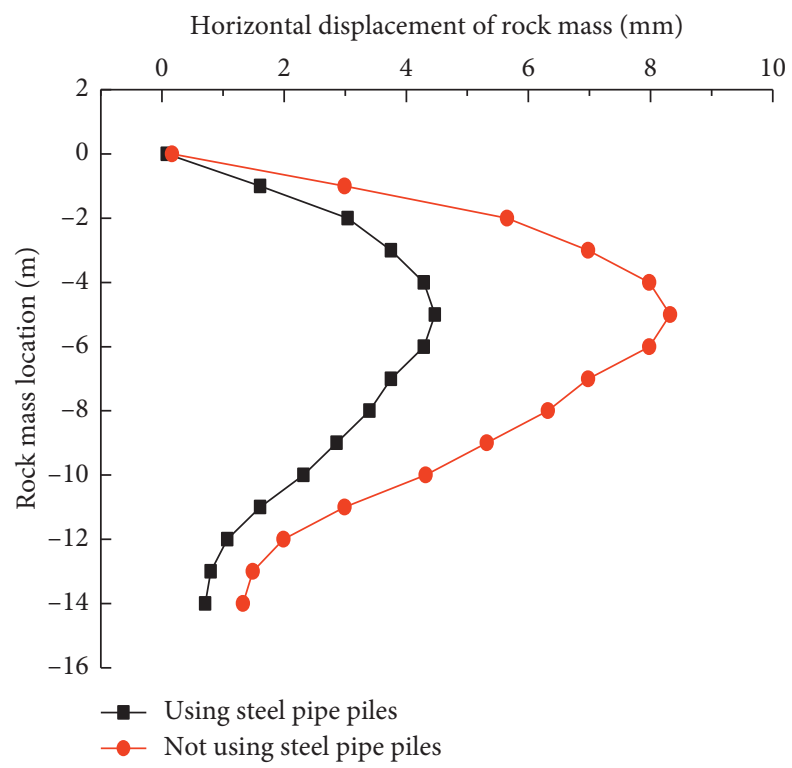

FIGURE 20: The horizontal displacement of rock mass with and without steel pipe piles. 


\section{Conclusions}

In this paper, the six pilot tunnels and three spans of the PBA method for underground excavation of metro stations with large sections are presented. The geological conditions suitable for this method are the upper-soft and lower-hard stratum in the Dalian city of China. This method made full use of the stability of rock mass, reduced the number of pilot tunnels, shortened the construction period, and reduced the project cost. The control effect of six pilot tunnels and three spans of the PBA method on the surface settlement is analyzed. We can draw the following conclusions from the research results:

(1) In the process of excavation of six pilot tunnels, the surface settlement caused by the lower pilot tunnels accounting for $51.6 \%$ of the total surface settlement in the construction stages of six pilot tunnels. The superposition effect of the upper and lower pilot tunnels has a great impact on the ground surface. The location of the largest surface settlement is at the centerline of the station.

(2) The pilot tunnel construction and the arch construction have a great influence on the ground surface. The part of the vertical support of the pilot tunnels is removed, which caused the change of position of maximum vertical stress and the redistribution of vertical stress, which greatly disturbed the ground surface and resulted in the large settlement of the ground surface.

(3) The ground surface settlement, vertical displacement of arches, support structure stress, and rock mass horizontal displacement are all less than the construction control value. The supporting system composed of arches and piles can ensure the safety of construction and the surrounding environment of the metro station.

(4) In the case of weak surrounding rock conditions, adding side piles on both sides of the station can effectively reduce the disturbance of construction to the surrounding rocks, and the surface settlement can also be effectively controlled.

\section{Data Availability}

The data used to support the findings of this study are available from the corresponding author upon request.

\section{Conflicts of Interest}

The authors declare that they have no conflicts of interest regarding the publication of this article.

\section{Acknowledgments}

This work was supported by the LiaoNing Revitalization Talents Program (Grant no. XLYC1905015) and the National Natural Science Foundation of China (Grant nos. 51678101 and 52078093).

\section{References}

[1] J. Lv, X. Li, Z. Li, and H. Fu, "Numerical simulations of construction of shield tunnel with small clearance to adjacent tunnel without and with isolation pile reinforcement," KSCE Journal of Civil Engineering, vol. 24, no. 1, pp. 295-309, 2020.

[2] X. L. Jiang, L. Li, J. Yuan, and J. X. Yin, "Dynamic analysis of strata horizontal displacements induced by shield construction of deep tunnel," Rock and Soil Mechanics, vol. 32, no. 4, pp. 1186-1192, 2010.

[3] M. R. B. Golpasand, N. A. Do, D. Dias, and M. R. Nikudel, "Effect of the lateral earth pressure coefficient on settlements during mechanized tunneling," Geomechanics and Engineering, vol. 16, no. 6, pp. 643-654, 2018.

[4] J. L. Yu and X. N. Gong, "Research on deformation of foundation-pit engineering," China Civil Engineering Journal, vol. 35, no. 4, pp. 86-90, 2002.

[5] D. C. Koutsoftas, P. Frobenius, C. L. Wu, D. Meyersohn, and R. Kulesza, "Deformations during cut-and-cover construction of MUNI metro turnback project," Journal of Geotechnical and Geoenvironmental Engineering, vol. 126, no. 4, pp. 344359, 2000.

[6] M. Shakeel and C. W. W. Ng, "Settlement and load transfer mechanism of a pile group adjacent to a deep excavation in soft clay," Computers and Geotechnics, vol. 96, pp. 55-72, 2018.

[7] G. Zheng, Z. X. Yan, H. Y. Lei, and Y. Lei, "Field observation and finite element numerical simulation analysis of effect on adjacent piles due to excavation," Chinese Journal of Geotechnical Engineering, vol. 29, no. 5, pp. 638-643, 2007.

[8] N. Q. Zhou, P. A. Vermeer, R. X. Lou, Y. Q. Tang, and S. M. Jiang, "Numerical simulation of deep foundation pit dewatering and optimization of controlling land subsidence," Engineering Geology, vol. 114, no. 3-4, pp. 251-260, 2010.

[9] B.-C. B. Hsiung, K.-H. Yang, W. Aila, and C. Hung, "Threedimensional effects of a deep excavation on wall deflections in loose to medium dense sands," Computers and Geotechnics, vol. 80, pp. 138-151, 2016.

[10] P.-G. Hsieh, C.-Y. Ou, and Y.-L. Lin, "Three-dimensional numerical analysis of deep excavations with cross walls," Acta Geotechnica, vol. 8, no. 1, pp. 33-48, 2012.

[11] X. Yang and Y. Li, "Research of surface settlement for a single arch long-span subway station using the Pipe-roof Pre-construction Method," Tunnelling and Underground Space Technology, vol. 72, pp. 210-217, 2018.

[12] K. A. Valizadeh, M. H. Sadaghiani, and M. M. Ahmadi, "Numerical modeling of ground settlement control of large span underground metro station in Tehran Metro using Central Beam Column (CBC) structure," Tunnelling and Underground Space Technology, vol. 28, pp. 1-9, 2012.

[13] W. B. Qu and X. R. Liu, "Internal force calculation of piles in metro station construction using PBA method," Chinese Journal of Underground Space and Engineering, vol. 9, no. 1, pp. 102-105, 2013.

[14] X. Liu, Y. Liu, W. Qu, and Y. Tu, "Internal force calculation and supporting parameters sensitivity analysis of side piles in the subway station excavated by Pile-Beam-Arch method," Tunnelling and Underground Space Technology, vol. 56, pp. 186-201, 2016.

[15] X. Liu, Y. Liu, Z. Yang, and C. He, "Numerical analysis on the mechanical performance of supporting structures and ground settlement characteristics in construction process of subway station built by Pile-Beam-Arch method," KSCE Journal of Civil Engineering, vol. 21, no. 5, pp. 1690-1705, 2017. 
[16] L. Yu, D. Zhang, Q. Fang, L. Cao, T. Xu, and Q. Li, "Surface settlement of subway station construction using pile-beamarch approach," Tunnelling and Underground Space Technology, vol. 90, pp. 340-356, 2019.

[17] B. Li and Z. Z. Wang, "Numerical study on the response of ground movements to construction activities of a metro station using the pile-beam-arch method," Tunnelling and Underground Space Technology, vol. 88, pp. 209-220, 2019.

[18] Q. Z. Chen, "Influence of excavation sequence of pilot tunnel with PBA method on surface subsidence in sand gravel stratum,” Railway Engineering, vol. 57, pp. 81-85, 2017.

[19] S. G. Huang, Z. Fu, and J. L. Wu, "Study of soil deformation caused by construction with PBA method," Journal of Railway Engineering Society, vol. 35, no. 1, pp. 11-16, 2018.

[20] F. Wang, S. H. He, J. Liu, and R. L. Cao, "Analysis of control standard for ground surface settlement in excavating metro station by shield tunnel combined with pile-beam-arch method," Rock and Soil Mechanics, vol. 33, no. 2, pp. 289-296, 2012.

[21] J. X. Ren and X. T. L. Cao, "Research on the surface settlement of subway station induced by PBA construction method," Journal of Railway Engineering Society, vol. 35, no. 9, pp. 88-92, 2018.

[22] T. Wang, W. N. Liu, C. M. Zhang, H. J. He, and X. G. Li, "Study of surface settlement and flexible joint pipeline deformation induced by metro station construction with PBA method," China Civil Engineering Journal, vol. 26, no. 9, pp. 155-161, 2012.

[23] X. X. Chen, W. B. Xie, S. G. Jing, and W. Z. Wei, "Determination of mechanics parameters of mining induced rock mass for numerical simulation," Journal of Mining \& Safety Engineering, vol. 23, pp. 341-345, 2006. 